\title{
Love Styles and Cardiovascular Responder Types
}

\author{
Kenta Matsumura (Corresponding author) \\ School of Mechanical Engineering, College of Science and Engineering, Kanazawa University \\ Kakuma-machi, Kanazawa, Ishikawa 920-1192, Japan \\ Tel: 81-76-264-6467 E-mail: kenta16moon@se.kanazawa-u.ac.jp \\ Takehiro Yamakoshi \\ Graduate School of Natural Science and Technology, Kanazawa University \\ Kakuma-machi, Kanazawa, Ishikawa 920-1192, Japan \\ Tel: 81-76-234-4739 E-mail: takehiro@kenroku.kanazawa-u.ac.jp \\ Peter Rolfe \\ Oxford BioHorizons Ltd \\ 31-33 Albion Place, Maidstone, Kent, ME14 5DZ, United Kingdom \\ $\&$ \\ Department of Automatic Measurement and Control, Harbin Institute of Technology \\ No.92, West Da-Zhi Street, Harbin, Heilongjiang 150001, China \\ Tel: 86-451-8641-2114 E-mail: a25062001@aol.com
}

Received: May 15, 2011 Accepted: June 2, $2011 \quad$ Published: December 1, 2011

doi:10.5539/ijps.v3n2p21 URL: http://dx.doi.org/10.5539/ijps.v3n2p21

\begin{abstract}
We examined the relationship between cardiovascular responder types and love styles. Cardiovascular responder types were measured as reactivity to a social speech task. Measures included heart rate (HR), systolic and diastolic blood pressure (SBP and DBP, respectively), pre-ejection period (PEP), and baroreceptor sensitivity (BRS). Love styles were measured using the 2nd version of Lee's Type Scale; a questionnaire developed based on Lee's color theory. Analyses revealed that Eros (physically attracted love) score was related to HR, SBP, and BRS reactivity, and that Mania (obsessive and jealous love) score was related to HR and BRS reactivity. These results suggest that passionate love style, including Eros and Mania, is associated with cardiovascular responder types.
\end{abstract}

Keywords: Romantic love, Cardio-vascular responses, Heart rate, Speech tasks

\section{Introduction}

There is accumulated social psychological and psychophysiological evidence suggesting that a pounding heart is associated with romantic attraction. For example, a pounding heart has been known to be one of the common responses when in the presence of a person to whom one feels romantic attraction (Fisher, 1998). On the other hand, actual heart rate changes, induced by false heart rate feedback (Valins, 1966), have been shown to facilitate romantic attraction to persons of the opposite sex viewed in photographs (Goldstein, Fink, \& Mettee, 1972; Stern, Botto, \& Herrick, 1972). Moreover, the well-known "suspension bridge study" (Dutton \& Aron, 1974) and its meta-analysis study (Foster, Witcher, Campbell, \& Green, 1998) have also demonstrated that heightened arousal, which could be measured as an increased heart rate (Baron, 1987; White, Fishbein, \& Rutsein, 1981), facilitates romantic attraction to a beautiful confederate.

One interesting observation concerning the above-mentioned pounding heart and romantic attraction variables is that both show striking inter-individual differences. In other words, some individuals have a heart that easily pounds, whilst others' rarely pounds (Kasprowicz, Manuck, Malkoff, \& Krantz, 1990; Sherwood, Dolan, \& Light, 1990; Sherwood et al., 1997). Similarly, some individuals are frequently hit by love's arrow, yet others 
seldom are (Hendrick \& Hendrick, 1986; Lee, 1977). The former and the latter are termed high / low heart rate responders and Eros / non-Eros love style according to Lee's color theory (1977), respectively. However, to our knowledge, there is no study that examines the relationship between heart rate responder type and Eros love style. This absence is somewhat curious considering that state dependent variables, including the extent to which one's heart pounds in the presence of the beloved and to which one is romantically attracted under a certain level of increased heart rate, are generally under the influence of their corresponding individual traits.

In the present study, we therefore examined the relationship between cardiovascular responder types and love styles. To attain this, we obtained these two traits independently. Firstly, cardiovascular responder types were measured and determined as reactivities to a social speech task. Because cardiovascular reactivities have been shown to be retained for more than ten years (Sherwood, et al., 1997) and across tasks (Kasprowicz, et al., 1990; Sherwood, Dolan, et al., 1990), the reactivities to an arbitrary task, as far as it induces large reactivity, such as a speech task, can be used to determine or directly reflect cardiovascular responder types. To classify possible responder types we measured five cardiovascular variables, that is: heart rate; systolic and diastolic blood pressure; pre-ejection period; and baroreflex sensitivity. Secondly, love styles were measured using the 2nd version of Lee's Type Scale (LETS-2; Matsui et al., 1990); a Japanese questionnaire developed to measure the six love styles according to Lee's typology (1977). The measured love styles are Eros (romantic and physically attracted love), Mania (obsessive and jealous love), Ludus (playful or game love), Pragma (calculating love), Storge (slowly developing and friendship-like love), and Agape (altruistic love). Our hypothesis was that a high heart rate responder would have a high Eros score.

\section{Methods}

\subsection{Participants}

27 young female undergraduates participated in this study. They were divided into five groups, each of which had 5 or 6 members, and they participated as the group. 5 participants were excluded because they had no male beloved or friend and, as such, did not complete the questionnaire. The final sample therefore consisted of 22 young females, with a mean age of 18.5 years $(\mathrm{SD}=0.7)$. All were freshmen or sophomore at University. None of them had a history of cardiovascular or pulmonary disease, nor used medication or smoked cigarettes. Participants were asked to maintain their regular life-style before the test, and to have no food or caffeine during the hour prior to the laboratory session. Written consent was given by every participant.

\subsection{Apparatus}

The study was performed in a $2 \mathrm{~m} \times 3 \mathrm{~m}$ sound-attenuated, temperature-controlled experimental room. The social speech task (described below) was controlled by a computer (Apple, MacBook Pro) in the control room and presented through a display (Mitsubishi, RDT17M) in the experimental room. In developing this task, much of the software code used in a previous study (Matsumura, Yamakoshi, \& Ida, 2009) was included. Participants were monitored using a web camera (Apple, iSight) with a condenser microphone (Rhode, NT2A), and their speech (described later) was recorded on the hard disc of a computer (Apple, Mac mini).

Blood pressure was measured noninvasively on a beat-to-beat basis with a finger cuff attached to the middle finger of the left hand and connected to a blood pressure monitor (Ohmeda, Finapres 2300). The electrocardiogram (ECG) and thoracic impedance cardiogram were obtained from four circumferential electrodes, placed around the neck and chest, and connected to an impedance cardiograph (NEC, NICOVIEW PA1100). These signals were amplified by biological amplifiers (NEC san-ei, 1253A), and sampled at a rate of $1000 \mathrm{~Hz}$ with a resolution of 16 bits using a data acquisition card (National Instruments, PCI-6036E) installed on a computer (Dell, Dimension 8200).

\subsection{Task}

A 6-min. social speech task was adopted as the controlled stimulus to measure cardiovascular responder types. Speech is a task that is better able to resemble many aspects of real-life situations than traditional laboratory ones, such as mental arithmetic and mirror tracing tasks (e.g., Kline et al., 2002). In this task, participants were required to make an interesting, imaginative and continuous speech using all three nouns presented in tandem on the computer display and replaced every minute. It did not matter whether the content of the speech in each minute was separated or sequential, but the participants had to try not to speak in a staccato fashion. The speech was recorded so that the experimenters and other participants could make later evaluations. The participants were informed of a small financial incentive; that is, the top one-third of the group would be awarded 200 Yen (about U.S.2.5\$) and the middle one-third 50 yen (about U.S.0.6\$), but the remainder would receive nothing. 


\subsection{Love Styles}

Lee's Type Scale 2nd version (LETS-2; Matsui, et al., 1990) was used to measure the love styles. This Japanese scale was developed to measure the romantic love of Japanese undergraduates according to Lee's color theory (1977). The validity and reliability of LETS-2 was confirmed in terms of factorial validity and internal and temporal consistency. This is one of the most frequently used questionnaires to measure love styles in Japan.

The LETS-2 scale consists of six subscales of Lee's color theory; that is, Eros (romantic and physically attracted love), Mania (obsessive and jealous love), Ludus (playful or game love), Storge (slowly developing and friendship-like love), Agape (altruistic love), and Pragma (calculating love). Each subscale then has nine items, except for Storge, which has eight. Each item is written in a Likert-type format, with response made on a 5-point response scale, with 1 indicating strong agreement and 5 indicating strong disagreement. The scores for the nine (eight for Storge) items in each subscale are summed, then subtracted from 46 (41 for Storge) to calculate each subscale score.

\subsection{Procedure}

5 or 6 participants, the members of one group, assembled in our laboratory at 9:30 a.m. After they had filled out the LETS-2 scale questionnaire, they were instructed as follows: (a) the experiment involves the conduct of a stressful task, but the details are not explained now. (b) The experiment is conducted individually, so come to the experimental room in turn. (c) The member who performs the task next must be standing by in another room. The order is decided randomly according to the student ID number in advance.

When the participants entered the experimental room individually, they were first given a complete description of the experiment and they signed an informed consent form. They were then fitted with instruments for cardiovascular monitoring by two female experimenters and were seated in a chair in an experimental room. A 12-min rest period (using the last 3-min as a baseline) was followed by 2-min preparation and then the 6-min social speech task was carried out. Finally a further 10-min period was used for another purpose and is thus not reported in this paper. Then, participants left the experimental room.

After all members finished the task, they came back to the experimental room again and evaluated the recorded speech performances of other members one by one using 100-point rating scale from the viewpoint of how interesting, imaginative, and fluent they were. Participants received the money in accordance with these ratings.

\subsection{Cardiovascular Measures \& Data Reduction}

Systolic and diastolic blood pressure (SBP and DBP, respectively) were determined on a beat-by-beat basis. Heart rate (HR) was calculated from R-R intervals of the ECG. Using the ECG and the impedance cardiograph signals, pre-ejection period (PEP), an inverse index of $\beta$ adrenalin mediated sympathetic activity, was determined with a 60-s ensemble-averaging technique (Sherwood et al., 1990). Baroreflex sensitivity (BRS), an index of parasympathetic activity, was calculated using the sequence method (Steptoe \& Sawada, 1989).

Beat-by-beat SBP, DBP, and HR were averaged over the 60-s periods, and then PEP and BRS were calculated for the same periods. These values were furthermore averaged to produce baseline and task values, respectively.

\subsection{Cardiovascular Responder Types}

Cardiovascular responder types have usually been defined as high or low by dichotomizing reactivities to a certain task (e.g., Beere, Glagov, \& Zarins, 1984; Manuck, Kaplan, \& Clarkson, 1983). However, such a degraded conversion of continuous to nominal scale involves loss of information (Gregg, Matyas, \& James, 2002; MacCallum, Zhang, Preacher, \& Rucker, 2002). So, in this study, we ventured to define cardiovascular responder types not as traditional high or low dichotomization, but as absolute values of task-induced delta $(\Delta)$ change reactivities, by subtracting baseline values from task values.

\section{Results}

All participants completed the experiment.

\subsection{LETS-2 Measures}

The summary of love style scores is presented in Table 1.

\subsection{Cardiovascular Measures}

The summary of cardiovascular measures during baseline and social speech task is presented in Table 2. The results of paired $t$-test and effect sizes are also shown in Table 2 . 


\subsection{The Relationships between Cardiovascular Responder Types and Love Styles}

The Pearson correlations were calculated between cardiovascular responder types expressed as $\Delta$ change reactivity and love style scores. The HR reactivity ( $\triangle \mathrm{HR}$; reflecting HR responder type) was positively associated with the Eros $(r=.45, p<.05)$ and Mania $(r=.44, p<.05)$ love scores, and negatively associated with Ludus love score $(r=-.46, p<.05)$ (see Table 3 and Figure 1$)$. As for the others, the Eros love score was associated with SBP $(r=.46, p<.05)$, BRS $(r=-.45, p<.05)$, and PEP $(r=-.40, p<.10)$ reactivity ( $\Delta$ SBP, $\triangle \mathrm{BRS}$, and $\triangle \mathrm{PEP}$; reflecting SBP, BRS, and PEP responder type, respectively) and the Mania love score was negatively associated with BRS $(r=-.46, p<.05)$ reactivity ( $\triangle \mathrm{BRS}$; reflecting BRS responder type). These results are presented together in Table 3 and Figure 1-4.

\section{Discussion}

This study revealed that five cardiovascular responder types, that is, HR, SBP, DBP, PEP, and BRS, expressed as $\Delta$ change reactivity, are differentially associated with six love style scores, that is, Eros, Mania, Ludus, Pragma, Storge, and Agape. As predicted, HR responder type was positively associated with the Eros love scores. Thus, we concluded that our hypothesis was supported. However, other relationships were also observed.

The Eros score was related to many cardiovascular responder types. Among these, SBP and inversed PEP are indices of $\beta$ adrenergic sympathetic activity, and BRS is that of parasympathetic activity. Because HR is well known to be adjusted by $\beta$ adrenergic sympathetic activity and parasympathetic activity, that is to say, the former as accelerator and the latter as brake, these are convergent results. For a given situation, HR can be modulated by either sympathetic or parasympathetic activity (Berntson, Cacioppo, \& Quigley, 1993), in this case both nerve systems are involved. Such a totality is clearly consistent with the notion that romantic attraction accompanies a wide range of bodily responses and intense emotions (Fisher, 1998).

The Mania score was also related to HR and BRS responder type, although limited numbers of relationships were observed as compared to the whole group of Eros scores. Considering that Mania and Eros were both classified into same category, that is, a passionate love style (Masuda, 2003; Rubin, 1970; Sternberg, 1987), these relationships were not surprising. As regards Mania, HR is predominantly modulated by parasympathetic activity.

The Ludus score was also associated with the HR responder type, and at first sight this is perhaps unexpected. However, considering the nature of Ludas (playful or game love), this finding is perhaps reasonable. This is because a lower HR responder may reduce the likelihood of loving one person passionately, which saves one's energy and enables one to have multiple lovers, which is often observed in Ludus style love.

Taken together, it is concluded that passionate love styles (Masuda, 2003; Rubin, 1970; Sternberg, 1987) such as Eros and Mania are related to cardiovascular responder types.

Following on from this conclusion we might introduce new insights into love-related research. For example, in the suspension bridge study (Dutton \& Aron, 1974), there were 9/18 participants who did not telephone a beautiful confederate in spite of accepting a phone number after crossing the suspension bridge. Nevertheless, there were many possibilities to explain why they did not telephone her, such as simply being shy or not having a liking for the confederate. However, our conclusion gives rise to a new possible explanation that they were lower HR responders. That is, lower HR responders hardly show increased HR even though they cross suspension bridge, so they would not be attracted by the beautiful confederate. New studies to test this hypothesis could be interesting.

Taking another example, the presence of a spouse has been shown to cause heightened cardiovascular response (Allen, Blascovich, \& Mendes, 2002). Considering that such temporal response should be under the influence of cardiovascular responder types, it seems likely that once one falls in love, these trait and state components could possibly form a positive feedback loop that serves to maintain passionate love. To examine this hypothesis, it would be possible to carry out studies using beloved related stimuli (Aron et al., 2005) and / or multiple sampling points along the developmental time course of love from initial passionate love to the later companionate love phase. Comparisons could also be made between before and after falling in love (Marazziti, Akiskal, Rossi, \& Cassano, 1999).

There are some limitations in our study. Firstly, our sample consisted of only female participants, and this finding needs to be replicated in male participants. Secondly, our finding has been made on the basis of simple correlations, and it should be tested by multivariate analysis to judge whether there is a third factor as a cause of the present relationships or possible correlates. Measures should include other major traits such as neuroticism and anxiety. Thirdly, we used only one stress task to define cardiovascular responder types. Although these 
tendencies have shown to be retained over ten years (Sherwood, et al., 1997) and across tasks (Kasprowicz, et al., 1990; Sherwood, Dolan, et al., 1990), it would have been preferable to use a stress task battery (Kamarck, Debski, \& Manuck, 2000). Despite these limitations, we have provided new evidence as to the relationship between love styles and cardiovascular responder types; that is, passionate love style is associated with cardiovascular responder types. We hope this study will trigger a wide range of studies on romantic love.

\section{References}

Allen, K., Blascovich, J., \& Mendes, W. B. (2002). Cardiovascular reactivity and the presence of pets, friends, and spouses: The truth about cats and dogs. Psychosomatic Medicine, 64(5), 727-739. http://dx.doi.org/10.1097/01.Psy.0000024236.11538.41

Aron, A., Fisher, H., Mashek, D. J., Strong, G., Li, H. F., \& Brown, L. L. (2005). Reward, motivation, and emotion systems associated with early-stage intense romantic love. Journal of Neurophysiology, 94(1), 327-337. http://dx.doi.org/10.1152/Jn.00838.2004

Baron, R. A. (1987). Effects of negative ions on interpersonal attraction: evidence for intensification. Journal of Personality and Social Psychology, 52(3), 547-553. http://dx.doi.org/10.1037/0022-3514.52.3.547

Beere, P. A., Glagov, S., \& Zarins, C. K. (1984). Retarding effect of lowered heart rate on coronary atherosclerosis. Science, 226(4671), 180-182. http://dx.doi.org/doi:10.1126/science.6484569

Berntson, G. G., Cacioppo, J. T., \& Quigley, K. S. (1993). Cardiac Psychophysiology and Autonomic Space in Humans - Empirical-Perspectives and Conceptual Implications. Psychological Bulletin, 114(2), 296-322. http://dx.doi.org/10.1037/0033-2909.114.2.296

Dutton, D. G., \& Aron, A. P. (1974). Some evidence for heightened sexual attraction under conditions of high anxiety. Journal of Personality and Social Psychology, 30(4), 510-517. http://dx.doi.org/10.1037/h0037031

Fisher, H. E. (1998). Lust, attraction, and attachment in mammalian reproduction. Human Nature, 9, 23-52. http://dx.doi.org/10.1007/s12110-998-1010-5

Foster, C. A., Witcher, B. S., Campbell, W. K., \& Green, J. D. (1998). Arousal and attraction: Evidence for automatic and controlled processes. Journal of Personality and Social Psychology, 74(1), 86-101. http://dx.doi.org/10.1037/0022-3514.74.1.86

Goldstein, D., Fink, D., \& Mettee, D. R. (1972). Cognition of arousal and actual arousal as determinants of emotion. Journal of Personality and Social Psychology, 21(1), 41-51. http://dx.doi.org/10.1037/h0031873

Gregg, M. E., Matyas, T. A., \& James, J. E. (2002). A new model of individual differences in hemodynamic profile and blood pressure reactivity. Psychophysiology, 39(1), 64-72. http://dx.doi.org/10.1017/S0048577202001154

Hendrick, C., \& Hendrick, S. (1986). A theory and method of love. Journal of Personality and Social Psychology, 50(2), 392-402. http://dx.doi.org/10.1037/0022-3514.50.2.392

Kamarck, T. W., Debski, T. T., \& Manuck, S. B. (2000). Enhancing the laboratory-to-life generalizability of cardiovascular reactivity using multiple occasions of measurement. Psychophysiology, 37(4), 533-542. http://dx.doi.org/10.1017/S0048577200990644

Kasprowicz, A. L., Manuck, S. B., Malkoff, S. B., \& Krantz, D. S. (1990). Individual-Differences in Behaviorally Evoked Cardiovascular-Response - Temporal Stability and Hemodynamic Patterning. Psychophysiology, 27(6), 605-619. http://dx.doi.org/10.1111/j.1469-8986.1990.tb03181.x

Kline, K. A., Saab, P. G., Llabre, M. M., Spitzer, S. B., Evans, J. D., McDonald, P. A. G., et al. (2002). Hemodynamic response patterns: Responder type differences in reactivity and recovery. Psychophysiology, 39(6), 739-746. http://dx.doi.org/10.1017/S0048577202000781

Lee, J. A. (1977). A Typology of Styles of Loving. Personality and Social Psychology Bulletin, 3(2), 173-182. http://dx.doi.org/10.1177/014616727700300204

MacCallum, R. C., Zhang, S., Preacher, K. J., \& Rucker, D. D. (2002). On the practice of dichotomization of quantitative variables. Psychological Methods, 7(1), 19-40. http://dx.doi.org/10.1037//1082-989X.7.1.19

Manuck, S. B., Kaplan, J. R., \& Clarkson, T. B. (1983). Behaviorally induced heart rate reactivity and atherosclerosis in cynomolgus monkeys. Psychosomatic Medicine, 45(2), 95-108

Marazziti, D., Akiskal, H. S., Rossi, A., \& Cassano, G. B. (1999). Alteration of the platelet serotonin transporter in romantic love. Psychological Medicine, 29(3), 741-745. http://dx.doi.org/10.1017/S0033291798007946 
Masuda, M. (2003). Meta-analyses of love scales: Do various love scales measure the same psychological constructs? Japanese Psychological Research, 45(1), 25-37. http://dx.doi.org/10.1111/1468-5884.00030

Matsui, Y., Tokusa, T., Tachizawa, H., Ohkubo, H., Ohmae, H., Okamura, M., et al. (1990). Scale construction of Japanese youths' love [in Japanese]. Tachikawa Junior College Bulletin, 23, 13-23

Matsumura, K., Yamakoshi, T., \& Ida, T. (2009). Performance measures of alcohol-induced impairment: towards a practical ignition-interlock system for motor vehicles. Perceptual and Motor Skills, 109(3), 841-850. http://dx.doi.org/10.2466/pms.109.3.841-850

Rubin, Z. (1970). Measurement of romantic love. Journal of Personality and Social Psychology, 16(2), 265-273. http://dx.doi.org/10.1037/h0029841

Sherwood, A., Allen, M. T., Fahrenberg, J., Kelsey, R. M., Lovallo, W. R., \& Vandoornen, L. J. P. (1990). Methodological Guidelines for Impedance Cardiography. Psychophysiology, 27(1), 1-23. http://dx.doi.org/10.1111/j.1469-8986.1990.tb02171.x

Sherwood, A., Dolan, C. A., \& Light, K. C. (1990). Hemodynamics of Blood-Pressure Responses during Active and Passive Coping. Psychophysiology, 27(6), 656-668. http://dx.doi.org/10.1111/j.1469-8986.1990.tb03189.x

Sherwood, A., Girdler, S. S., Bragdon, E. E., West, S. G., Brownley, K. A., Hinderliter, A. L., et al. (1997). Ten-year stability of cardiovascular responses to laboratory stressors. Psychophysiology, 34(2), 185-191. http://dx.doi.org/10.1111/j.1469-8986.1997.tb02130.x

Steptoe, A., \& Sawada, Y. (1989). Assessment of baroreceptor reflex function during mental stress and relaxation. Psychophysiology, 26(2), 140-147. http://dx.doi.org/10.1111/j.1469-8986.1989.tb03145.x

Stern, R. M., Botto, R. W., \& Herrick, C. D. (1972). Behavioral and physiological effects of false heart rate feedback: a replication and extension. Psychophysiology, 9(1), 21-29. http://dx.doi.org/10.1111/j.1469-8986.1972.tb00739.x

Sternberg, R. J. (1987). Liking versus loving: A comparative evaluation of theories. Psychological Bulletin, 102(3), 331-345. http://dx.doi.org/10.1037/0033-2909.102.3.331

Valins, S. (1966). Cognitive effects of false heart-rate feedback. Journal of Personality and Social Psychology, 4(4), 400-408. http://dx.doi.org/10.1037/h0023791

White, G. L., Fishbein, S., \& Rutsein, J. (1981). Passionate love and the misattribution of arousal. Journal of Personality and Social Psychology, 41(1), 56-62. http://dx.doi.org/10.1037/0022-3514.41.1.56

Table 1. Mean $(S D)$ scores of Lee's type scale 2nd version (LETS-2) $(N=22)$

\begin{tabular}{|c|c|}
\hline Love Styles & Mean $(S D)$ \\
\hline Eros & $16.3(9.6)$ \\
\hline Mania & $17.2(9.2)$ \\
\hline Ludus & $14.9(5.8)$ \\
\hline Pragma & $15.6(6.7)$ \\
\hline Storge & $15.1(6.4)$ \\
\hline Agape & $17.4(8.0)$ \\
\hline
\end{tabular}

Note. Eros = physically attracted love; Mania $=$ obsessive and jealous love; Ludus = playful or game love; Storge $=$ slowly developing and friendship-like love; Agape $=$ altruistic love; Pragma $=$ calculating love. Possible range: 1-37, except for Stroge: 1-33. 
Table 2. Mean $(S D)$ values of cardiovascular measures at baseline and during social speech task $(N=22)$

\begin{tabular}{|c|c|c|c|c|c|}
\hline \multirow{2}{*}{} & \multirow{2}{*}{$\begin{array}{c}\text { Cardiovascular } \\
\text { Index }\end{array}$} & \multicolumn{2}{|c|}{ Stress Tasks } & \multicolumn{2}{c|}{ Statistical Analyses } \\
\cline { 3 - 6 } & Baseline & Speech & $t_{(21)}$ & $d$ \\
\hline \multirow{3}{*}{$\begin{array}{c}\text { Hemo- } \\
\text { dynamics }\end{array}$} & HR $(\mathrm{bpm})$ & $73.8(8.3)$ & $90.0(12.6)$ & $7.88^{* * *}$ & 1.52 \\
\cline { 2 - 6 } & SBP $(\mathrm{mmHg})$ & $122.5(20.5)$ & $161.2(20.8)$ & $13.19^{* * *}$ & 1.88 \\
\cline { 2 - 6 } & $\mathrm{DBP}(\mathrm{mmHg})$ & $68.7(10.6)$ & $88.6(10.4)$ & $14.78^{* * *}$ & 1.90 \\
\hline \multirow{2}{*}{$\begin{array}{c}\text { Autonimic } \\
\text { Activities }\end{array}$} & $\mathrm{PEP}(\mathrm{ms})$ & $105.8(13.9)$ & $93.9(13.7)$ & $8.68^{* * *}$ & 0.86 \\
\cline { 2 - 6 } & $\mathrm{BRS}(\mathrm{ms} / \mathrm{mmHg})$ & $10.7(3.7)$ & $7.9(2.9)$ & $3.68^{* *}$ & 0.84 \\
\hline
\end{tabular}

Note. $\mathrm{HR}=$ heart rate; $\mathrm{SBP}$ = systolic blood pressure; $\mathrm{DBP}$ = diastolic blood pressure; $\mathrm{PEP}$ = pre-ejection period; $\mathrm{BRS}=$ baroreflex sensitivity.

${ }^{* * *} p<.001, \stackrel{* *}{p}<.01$.

Table 3. The correlation coefficient between love styles and cardiovascular responder types $(N=22)$

\begin{tabular}{|c|c|c|c|c|c|c|c|}
\hline & \multirow{2}{*}{$\begin{array}{c}\text { Cardiovascular } \\
\text { Responder Types }\end{array}$} & \multicolumn{6}{|c|}{ Love Styles } \\
\cline { 3 - 8 } & & Eros & Mania & Ludus & Pragma & Storge & Agape \\
\hline \multirow{3}{*}{$\begin{array}{c}\text { Hemo- } \\
\text { dynamics }\end{array}$} & $\Delta$ HR (bpm) & $.45^{*}$ & $.44^{*}$ & $-.46^{*}$ & -.10 & -.34 & .30 \\
\cline { 2 - 8 } & $\Delta \mathrm{SBP}(\mathrm{mmHg})$ & $.46^{*}$ & .24 & -.09 & .33 & .10 & .27 \\
\cline { 2 - 8 } & $\Delta \mathrm{DBP}(\mathrm{mmHg})$ & .28 & .19 & -.12 & .25 & .02 & .10 \\
\hline \multirow{2}{*}{$\begin{array}{c}\text { Autonimic } \\
\text { Activities }\end{array}$} & $\Delta \mathrm{PEP}(\mathrm{ms})$ & $-.40^{+}$ & -.18 & .04 & -.28 & -.07 & -.24 \\
\cline { 2 - 8 } & $\Delta \mathrm{BRS}(\mathrm{ms} / \mathrm{mmHg})$ & $-.45^{*}$ & $-.46^{*}$ & .11 & .17 & .19 & -.23 \\
\hline
\end{tabular}

Note. $\mathrm{HR}=$ heart rate; $\mathrm{SBP}$ = systolic blood pressure; $\mathrm{DBP}=$ diastolic blood pressure; $\mathrm{PEP}=$ pre-ejection period; $\mathrm{BRS}=$ baroreflex sensitivity.

Eros $=$ physically attracted love; Mania $=$ obsessive and jealous love; Ludus = playful or game love; Storge = slowly developing and friendship-like love; Agape = altruistic love; Pragma = calculating love. ${ }^{*} p<.05,{ }^{+} p<.10$.
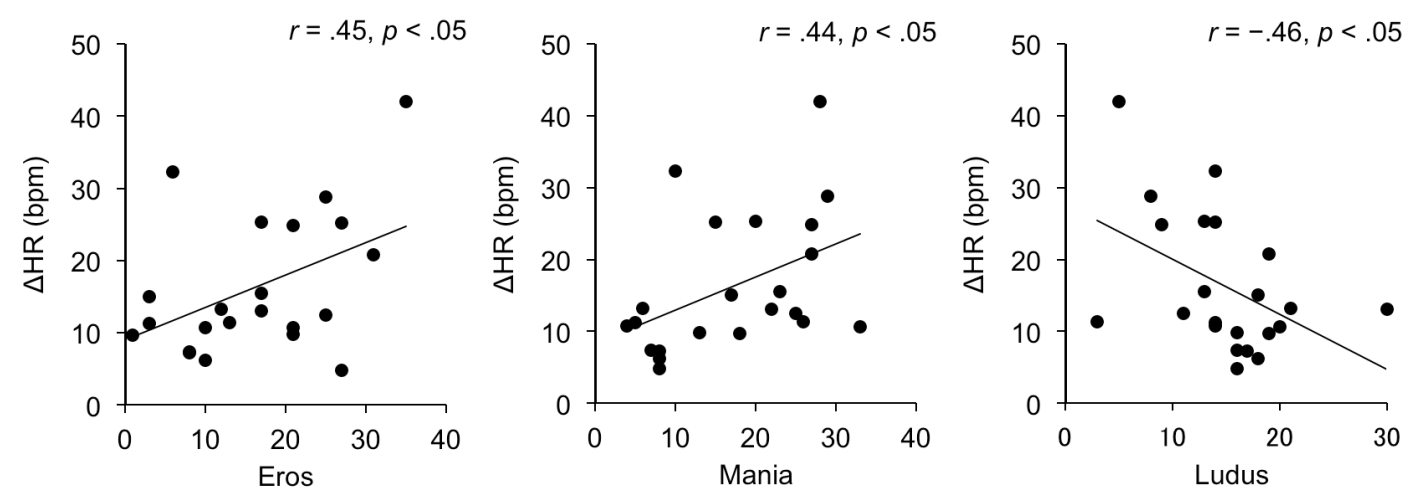

Figure 1. Scatter plot between heart rate reactivity ( $\triangle \mathrm{HR}$; reflecting HR responder type) and Eros (physically attracted love; left), Mania (obsessive and jealous love; middle), and Ludus (playful or game love ; right) score 

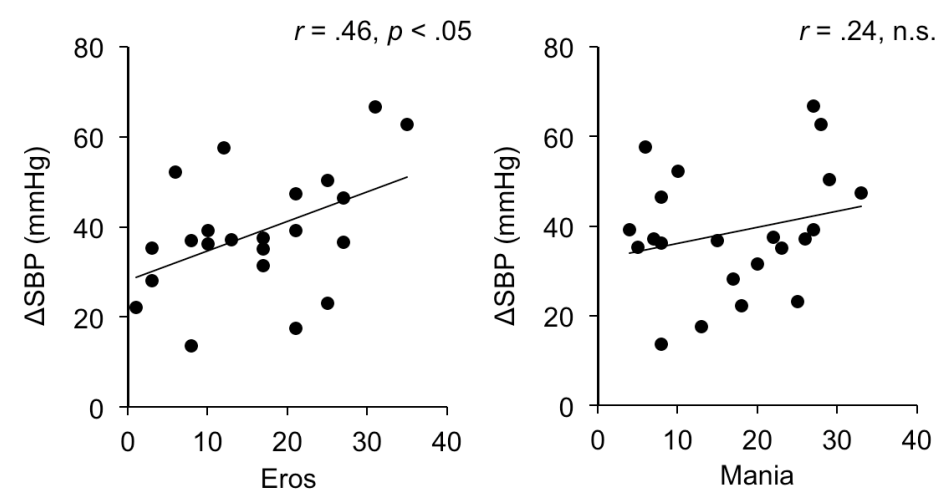

Figure 2. Scatter plot between systolic blood pressure reactivity ( $\triangle \mathrm{SBP}$; reflecting SBP responder type) and Eros (physically attracted love; left) and Mania (obsessive and jealous love; right) score
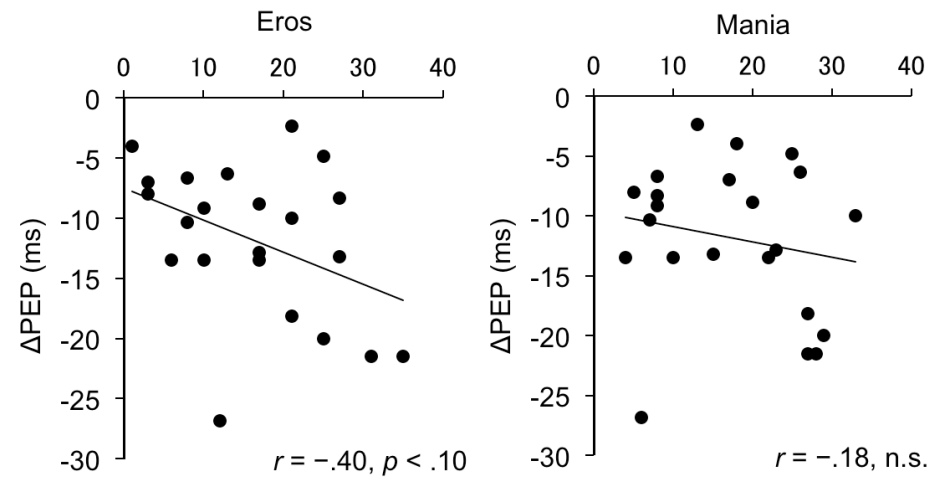

Figure 3. Scatter plot between pre-ejection period reactivity ( $\triangle \mathrm{PEP}$; reflecting PEP responder type) and Eros (physically attracted love; left) and Mania (obsessive and jealous love; right) score
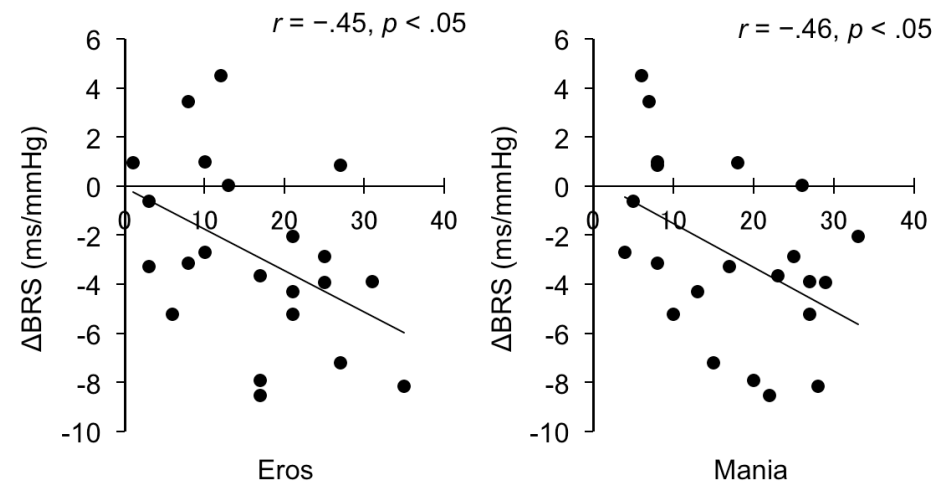

Figure 4. Scatter plot between baroreflex sensitivity reactivity ( $\triangle \mathrm{BRS}$; reflecting BRS responder type) and Eros (physically attracted love; left) and Mania (obsessive and jealous love; right) score 